\title{
ESTABLISHING SUSTAINABLE HANDWASHING WATER STRATEGIES TO MANAGE THE SPREAD OF COVID-19
}

\author{
Asayehgn Desta, Dominican University of California, San Rafael, U.S.A. \\ Hadush Berhe, Mekelle University, Ethiopia
}

dx.doi.org/10.18374/JABE-20-3.3

\begin{abstract}
As the pandemic of COVID-19 spread across the world, Ethiopia undertook monetary and fiscal stimulus packages and also attempted to shoulder various preventive health-related measures such as staying at home, handwashing with clean water, mask-wearing, and maintaining proper social distancing to suppress the spread of the COVID-19 virus. The objective of the study was to review the effectiveness of monetary, fiscal stimulus packages, and assess the health-related preventive measures that have been used to mitigate the economic outbreaks caused by the COVID-19 pandemic. The primary questions of the study included: 1) Do monetary and fiscal stimulus packages minimize the economic shocks caused by the coronavirus pandemics? and 2) Do health-related preventive measures alleviate the damages from COVID-19? The sole sources of information for study were based on secondary data. The principal findings of study include that since Ethiopia, prior to COVID-19, was faced with a fragile economic environment and poor health infrastructure, the demand management policies that it undertook had limited impact to spark the subdued Ethiopia's economy. As the costs of the stringent health-related preventive measures applied to Ethiopian situation outstripped their benefits, their effects were less fruitful. The staying-at-home policy contributed to the deaths of poor people from starvation. Maintaining social distancing did not slow the threat the coronavirus in Ethiopia because 4 to 5 family members share one room. Mask-wearing of mouth and eyes is the only affordable and feasible device that could be implemented to fight against COVID-19 in Ethiopia. Given that Tigray has limited access to basic handwashing facilities, policy makers need to design a combination of on-site water recycling or water downcycling and rainwater harvesting to reduce water shortage in Tigray and combat the future occurrence and spread of disease like the COVID-19, while staying vigilant of the second wave of infections.
\end{abstract}

Keywords: Coronavirus, COVID-19, Monetary and Fiscal Policies Stimulants, Staying at home, Hand washing, Mask-wearing, Social distancing 